\title{
Designing of fuzzy expert heuristic models with cost management toward coordinating AHP, fuzzy TOPSIS and FIS approaches
}

\author{
ANUP KUMAR RAJAK*, MALAY NIRAJ and SHALENDRA KUMAR \\ Department of Mechanical Engineering, National Institute of Technology, Jamshedpur 831014, India \\ e-mail: 2012rsme008@nitjsr.ac.in; malay931@gmail.com; shalkumar.me@ nitjsr.ac.in
}

MS received 24 October 2015; revised 11 May 2016; accepted 12 May 2016

\begin{abstract}
In genuine industrial case, problems are inescapable and pose enormous challenges to incorporate accurate sustainability factors into supplier selection. In this present study, three different primarily based multicriteria decision making fuzzy models have been compared with their deterministic version so as to resolve fuzzy prioritization problems. The developed model applies AHP, TOPSIS and fuzzy inference system (FIS) using a MATLAB toolbox to effectively analyze the interdependencies between sustainability criteria and select the best sustainable supplier in the fuzzy environment, while capturing all objective criteria. A typical supplier A4 has been awarded the most suitable supplier with 0.386 composite relative weights of AHP, relative closeness to ideal solution 0.7154 and normalized score index 0.219 FIS model using MATLAB toolbox.
\end{abstract}

Keywords. AHP; fuzzy TOPSIS; fuzzy inference system (FIS); multi-criteria decision making (MCDM); supplier selection.

\section{Introduction}

In today's global era, individual firms compete in a complex and rapidly changing environment. Currently, supplier selection is a crucial activity of the supply chain of acquisition as its results have a great impact on quality of products and performance of organizations [1]. Multi-criteria decision making (MCDM) consists of a finite set of alternatives among which a decision maker has to select or rank, a finite set of criteria weighed according to their importance. The evaluation ratings are, then, aggregated taking into account the weights of the criteria to get a global evaluation of each alternative and a total ranking of the alternatives [2].

This paper is organized as follows: section 2 reviews some of the most popular approaches of MCDM and fuzzy based. Section 3 briefly describes how the total procurement cost is affected by faulty products supply and delay in delivery. Section 4 presents the sustainable criteria which are relevant to supplier selection according to past articles. Section 5 presents a descriptive approach of AHP, fuzzy TOPSIS and fuzzy inference system (FIS) algorithms and applied to the selection of the best suppliers of a company. Section 6 illustrates the results using proposed mathematical modeling by applying it on typical data of an organization in the real case application. Finally, conclusions and future scope of research are detailed.

*For correspondence

\section{Literature survey}

Conventionally, supplier selection problem is based on cost, quality and delivery of the parts. Consideration of all other aspects increases the complexity of the problem. There are various methods used for decision making, such as the analytic hierarchy process (AHP), technique for order preference by similarity to ideal solution (TOPSIS), simple additive weighting (SAW), multiplicative exponential weighting (MEW), etc. [2]. In 1966 most significant criteria were the "quality of the product", "on time delivery", "performance history" of the supplier and the warranty policy used by the supplier [3]. Weber et al [4] examined 74 articles and categorized these articles based on Dickson 23 supplier selection criteria. The researchers found out 85 criteria from the exploratory literature review and discussions with industrial professionals of Indian automobile manufacturers [5]. The supplier selection problem has been dragging the attention of the researchers and practitioners in the vicinity of supply chain management study over the decades [6]. The vendor selection problem has been developed using value engineering with traditional aspects of performance like quality, service, cost, delivery, reliability and general reputation [7].

Ertugrul and Karakasoglu [8] report a comparison of fuzzy AHP and fuzzy TOPSIS methods applied to facility location decision making. TOPSIS has been widely applied to the research of evaluation and selection problems and risk analysis problems [9-14]. AHP and TOPSIS in fuzzy 
environment can be integrated for a more consistent evaluation and prioritization of trading partner based on factor analysis of survey data and expert opinion $[15,16]$.

\section{Problem definition}

The comprehensive literature review reveals that there is a need to integrate the AHP, TOPSIS and FIS while considering 21 sustainable criteria in this fuzzy environment. The objective of this paper is to mathematically formulate the sustainable criteria and present an integrated model of AHP, TOPSIS and FIS MATLAB fuzzy tool for prioritization problems of alternatives in the supply chain. With the results of most sustainable supplier, illustrates the cost analysis of an organization.

In this paper a case of the leading automobile company in India has been considered to derive the multi-objective mathematical model. This firm constructs commercial, personal and army vehicles in large scale. Owing to high demand, this company requires various raw materials, semi-finished materials and other finished parts of the vehicle like speedometer, chassis, axle, electrical wires, sensors, seats, steering system, transmission system, etc. Each raw material supplied by the supplier would have different constraints and characteristic such as percentage of faulty material supplied, percentage delay in delivery and unit purchasing cost of the materials. The firm has specified the requirement of material within a certain period. If the raw material $i$ is being supplied by the supplier $k$, then the initial procurement cost is defined as

$$
P C=\sum_{i=1}^{j} \sum_{k=1}^{l} \alpha_{i k} Q_{i k},
$$

where $\alpha_{i k}$ is the unit cost of $i$ th material supplied by $k$ th supplier, and $Q_{i k}$ is the amount of material type $i$ procured by $k$ th supplier.

The total substandard delivery is defined as

$$
D C=\sum_{i=1}^{j} \sum_{k=1}^{l} \beta_{i j} Q_{i j},
$$

where $\beta_{i j}$ is the percentage of faulty items of $i$ th material supplied by $k$ th supplier, and $Q_{i k}$ is the amount of material type $i$ procured by $k$ th supplier.

Total delay in delivery is defined as

$$
D d=\sum_{i=1}^{j} \sum_{k=1}^{k} \gamma_{i k} Q_{i k},
$$

where $\gamma_{i k}$ is the delay percentage in delivery of $i$ th material supplied by $k$ th supplier, and $Q_{i k}$ is the amount of material type $i$ procured by $k$ th supplier.
In the supplier selection of an automobile industry the three basic objectives are simultaneously considered.

(1) Compute the total procurement cost.

(2) Compute the total number of faulty items supplied.

(3) Compute the total number of delay days in delivery in procuring various raw materials from various suppliers.

$$
Q C=(7+D d) \times D C .
$$

Hence the proposed multi-objective model aims to compute the total cost function

$$
f(x)=P C+Q C .
$$

Subject to

$$
\begin{aligned}
Q_{i k} & \leq x_{i k} \\
\sum_{k=1}^{l} Q_{i k} & \geq y_{i k},
\end{aligned}
$$

where $x_{i k}$ is the capacity of supplier $k$ while supplying material $i$, and $y_{i k}$ is the demand of material $i$ to the firm in certain period.

\section{Research methodologies}

\subsection{Analytic hierarchy process (AHP)}

Analytic hierarchy process (AHP) is a multi-criteria method of analysis based on additive weighing process, in which several relevant attributes are represented through their relative importance. It takes the pairwise comparisons of different alternatives with respective to various criteria and provides a decision support tool for multi-criteria decision problems. The steps of the procedure are as follows:

Step 1. Identification of criteria (building the evaluation hierarchy system).

Step 2. Determination of the weight of criteria.

Step 3. Effective criteria and pairwise comparison.

Step 4. Priority weight of alternatives and consistency analysis.

\section{1a Formulation of local fuzzy relative weight}

Normalization: For a matrix of pairwise element

$$
\left[\begin{array}{lll}
C_{11} & C_{12} & C_{13} \\
C_{21} & C_{22} & C_{23} \\
C_{31} & C_{32} & C_{33}
\end{array}\right] .
$$

Sum the values in each column of the pairwise matrix

$$
C_{i j}=\sum_{i=1}^{n} C_{i j} \text {. }
$$

Divide each element in the matrix by its column total to generate a normalized pairwise matrix 


$$
X_{i j}=\frac{C_{i j}}{\sum_{i=1}^{n} C_{i j}}\left[\begin{array}{lll}
X_{11} & X_{12} & X_{13} \\
X_{21} & X_{22} & X_{23} \\
X_{31} & X_{32} & X_{33}
\end{array}\right] .
$$

Divide the sum of the normalized column of the matrix of the number of criteria used (n) to generate a weighed matrix

$$
W_{i j}=\frac{\sum_{j=1}^{n} X_{i j}}{n}\left[\begin{array}{l}
W_{11} \\
W_{21} \\
W_{31}
\end{array}\right] \text {. }
$$

\section{1b Consistency analysis}

Consistency vector is calculated by multiplying the pairwise matrix by weighed vector

$$
\left[\begin{array}{lll}
C_{11} & C_{12} & C_{13} \\
C_{21} & C_{22} & C_{23} \\
C_{31} & C_{32} & C_{33}
\end{array}\right] \times\left[\begin{array}{l}
W_{11} \\
W_{21} \\
W_{31}
\end{array}\right]=\left[\begin{array}{l}
C_{v_{11}} \\
C_{v_{21}} \\
C_{v_{31}}
\end{array}\right]
$$

Then it is accomplished by dividing the weighed sum vector with criterion weighed.

$$
\begin{gathered}
C_{v_{11}}=\frac{1}{W_{11}}\left[C_{11} W_{11}+C_{12} W_{21}+C_{13} W_{31}\right] \\
C_{v_{21}}=\frac{1}{W_{21}}\left[C_{21} W_{11}+C_{22} W_{21}+C_{23} W_{31}\right] \\
C_{v_{31}}=\frac{1}{W_{31}}\left[C_{31} W_{11}+C_{32} W_{21}+C_{33} W_{31}\right] .
\end{gathered}
$$

AHP procedure requires the computation of the consistency ratio to ensure the precision of the obtained solution. The consistency index $(C I)$ of pairwise comparison matrix is calculated using

$$
\begin{aligned}
& \lambda_{\max }=\sum_{i=1}^{n} C_{v_{i j}} \\
& C I=\frac{\lambda_{\max }-n}{n-1} .
\end{aligned}
$$

where $\lambda_{\max }$ Eigen value and $C I$ consistency index.

The random consistency index (RI) and consistency ratio (CR) are compared as

$$
\begin{gathered}
R I=1.98 \frac{n-2}{n} \\
C R=\frac{C I}{R I} .
\end{gathered}
$$

\section{1c Global composite relative weight}

\begin{tabular}{ccccc} 
& $W_{C_{1}}$ & $W_{C_{2}}$ & $\cdots$ & $W_{C_{n}}$ \\
\hline & $C_{1}$ & $C_{2}$ & $\cdots$ & $C_{n}$ \\
\hline$A_{1}$ & $W_{A_{1} C_{1}}$ & $W_{A_{1} C_{2}}$ & $\cdots$ & $W_{A_{1} C_{n}}$ \\
$A_{2}$ & $W_{A_{2} C_{1}}$ & $W_{A_{2} C_{2}}$ & $\cdots$ & $W_{A_{2} C_{n}}$ \\
$\cdots$ & $\cdots$ & $\cdots$ & $\ddots$ & $\cdots$ \\
$A_{m}$ & $W_{A_{m} C_{1}}$ & $W_{A_{m} C_{2}}$ & $\cdots$ & $W_{A_{m} C_{n}}$
\end{tabular}

Criteria $C_{j}(j=1,2, \ldots, n)$ and their corresponding weights

$$
\begin{gathered}
O_{A_{1}}=W_{C_{1}} W_{A_{1} C_{1}}+W_{C_{2}} W_{A_{1} C_{2}}+\cdots+W_{C_{n}} W_{A_{1} C_{n}} \\
O_{A_{2}}=W_{C_{1}} W_{A_{2} C 1}+W_{C_{2}} W_{A_{2} C_{2}}+\cdots+W_{C_{n}} W_{A_{2} C_{n}} \\
O_{A_{m}}=W_{C_{1}} W_{A_{m} C 1}+W_{C_{2}} W_{A_{m} C_{2}}+\cdots+W_{C_{n}} W_{A_{m} C_{n}}
\end{gathered}
$$

Weight of alternatives $A_{i}(i=1,2, \ldots, m)$ w.r.t. Criteria $C_{j}(j$ $=1,2, \ldots, n)$.

\subsection{Fuzzy TOPSIS}

\section{2a Establishing triangular fuzzy number}

The TOPSIS method was first proposed by Hwang and Yoon [17]. The mathematical concept borrowed for multicriteria decision making (MCDM) $[18,19]$. The steps of the fuzzy TOPSIS algorithm can be constructed in detail as follows:

\section{2b Establishment of the decision matrix}

The first step of the TOPSIS method involves the construction of a decision matrix $(D M)$. The TOPSIS method evaluates the following $D M$, which refers to $m$ alternatives and are evaluated in terms of $n$ criteria:

$$
D M=\left[\begin{array}{cccc}
C_{1} & C_{2} & \cdots & C_{n} \\
x_{11} & x_{12} & \cdots & x_{1 n} \\
x_{21} & x_{22} & \cdots & x_{2 n} \\
\vdots & \vdots & \ddots & \vdots \\
x_{m 1} & x_{m 2} & \cdots & x_{m n}
\end{array}\right]
$$

where ' $i$ ' is the criterion index $(i=1,2,3, \ldots, m)$; $m$ is the number of potential sites and ' $j$ ' is the alternative index $(j=1,2,3, \ldots, n)$. The elements $C_{1}, C_{2}, \ldots, C_{n}$ refer to the criteria. Where $x_{i j}$ denotes the performance measure of the $i$ th alternatives in terms of $j$ th criterion.

Step 1: Construction of the normalized decision matrix

TOPSIS converts the various criteria, dimensions into non-dimensional criteria as done in the ELECTRE method. An element $r_{i j}$ of the normalized decision matrix $R$ is thus calculated as-

$$
r_{i j}=\frac{x_{i j}}{\sqrt{\sum_{k=1}^{m} x_{i j}^{2}}} .
$$

Step 2: Construction of the weighed normalized decision matrix

$$
\begin{aligned}
v_{i j} & =w_{j} \times r_{i j} \\
v_{i j} & =\left[\begin{array}{cccc}
w_{1} r_{11} & w_{2} r_{12} & \cdots & w_{n} r_{1 n} \\
w_{1} r_{21} & w_{2} r_{22} & \cdots & w_{n} r_{2 n} \\
\vdots & \vdots & \ddots & \vdots \\
w_{1} r_{m 1} & w_{2} r_{m 2} & \cdots & w_{n} r_{m n}
\end{array}\right] .
\end{aligned}
$$


A set of weights $W=w_{1}, w_{2}, w_{3}, \ldots w_{n}$ defined by the decision maker is used with the decision matrix to generate the weighed normalized decision matrix $v_{i j}$ as follows.

Step 3: Determination of the positive ideal and negative ideal solutions

The Positive ideal denoted as $A^{+}$and the negative ideal denoted as $A^{-}$, alternatives (solutions) are defined as follows:

$$
\begin{aligned}
& A^{+}=\left\{v_{1}^{+}, v_{2}^{+}, v_{3}^{+} \ldots, v_{n}^{+}\right\}, \quad \text { where } \quad v_{j}^{+}=\left\{\left(\max \left(v_{i j}\right)\right.\right. \text { if } \\
&\left.j \in J) ; \quad\left(\min \left(v_{i j}\right) \text { if } j \in J^{\prime}\right), \quad i=1,2,3, \ldots, m\right\} . \\
& A^{-}=\left\{\begin{array}{l}
\left\{v_{1}^{-}, v_{2}^{-}, v_{3}^{-} \ldots, v_{n}^{-}\right\}, \quad \text { where } \quad v_{j}^{-}=\left\{\left(\min \left(v_{i j}\right)\right.\right. \text { if } \\
\\
\left.j \in J) ; \quad\left(\max \left(v_{i j}\right) \text { if } j \in J^{\prime}\right), \quad i=1,2,3, \ldots, m\right\} .
\end{array}\right.
\end{aligned}
$$

where $J=\{j=1,2,3, \ldots, n$ and $j$ is associated with the benefit criteria $\}$ and $J^{\prime}=\{j=1,2,3, \ldots, n$ and $j$ is associated with cost/lost criteria $\}$.

The previous two alternatives are fictitious. However, it is reasonable to assume here that for benefit criteria, the decision maker wants to have a maximum value among the alternatives.

Step 4: Calculation of the separation measure

The distance of each alternative from fuzzy positive ideal solution (FPIS) $\left(d_{i}^{+}\right)$and fuzzy negative ideal solution (FNIS) $\left(d_{i}^{-}\right)$has been computed. According to the vertex method, the distance between two triangular fuzzy numbers $A_{1}\left(l_{1}, m_{1}, u_{1}\right)$ and $A_{2}\left(l_{2}, m_{2}, u_{2}\right)$ have been calculated as:

$$
d\left(A_{1}, A_{2}\right)=\sqrt{\frac{1}{3}\left[\left(l_{1}-l_{2}\right)^{2}+\left(m_{1}-m_{2}\right)^{2}+\left(u_{1}-u_{2}\right)^{2}\right]} .
$$

Thus, for the distances from the positive ideal solution we have

$$
d_{i}^{+}=\sqrt{\sum_{j=1}^{n} d\left(v_{i j}, v_{j}^{+}\right)^{2}} \text { for } i=1,2,3, \ldots, m
$$

where $d_{i}^{+}$is the distance of each alternative from the positive ideal solution.

$$
d_{i}^{-}=\sqrt{\sum_{j=1}^{n} d\left(v_{i j}, v_{j}^{-}\right)^{2}} \text { for } i=1,2,3, \ldots, m
$$

where $d_{i}^{-}$is the distance of each alternative from the negative ideal solution.

Step 5: Calculation of the relative closest to the ideal solution

The relative closeness of an alternative $A_{i}$ with respect to the ideal solution $A^{+}$is defined as follows

$C_{i}=\frac{d_{i}^{-}}{d_{i}^{+}+d_{i}^{-}} \quad$ where $\quad 1 \geq C_{i} \geq 0 \quad$ and $\quad i=1,2,3, \ldots, m$.
Step 6: Ranking of the preference order

The best alternative can be decided according to the preference rank order of $C_{i}$. Therefore, the best alternative is the one which has the shortest distance to the ideal solution.

\subsection{Fuzzy inference system (FIS) using MATLAB toolbox}

Fuzzy inference refers to the computational procedures used for evaluating fuzzy linguistic descriptions using concepts such as membership functions, fuzzy logic operators, and if-then rules [20]. Since fuzzy logic allows us to mesh a quantitative approach with qualitative representation, it is used to quantify certain qualifiers such as; approximately, often, rarely, several, few and very [21]. The most common Mamdani and Sugeno approaches are used to fuzzy reasoning [22]. Here, we are using Mamdani approach. The proposed methodology consists of six main phases: To compute the output of this FIS given the inputs, following six steps have been used:

(a) Determining a set of fuzzy rules.

(b) Fuzzifying the inputs using the input membership functions.

(c) Combining the fuzzified inputs according to the fuzzy rules to establish rule strength.

(d) Finding the consequence of the rule of combining the rule strength and the output membership function.

(e) Combining the consequences to get an output distribution.

(f) Defuzzifying the output distribution (this step is only if a crisp output (class) is needed).

The sixth step is followed by rank ordering using SAW [23]. The SAW calculates score $S_{j}$ for each supplier. Then the score $S_{j}$ are normalized by calculating the index $K_{i}$, which leads to a normalized ranking of alternatives. Finally we select the best sustainable supplier with maximum index value of $K_{i}$.

$$
\begin{gathered}
S_{j}=\sum_{k} W_{k} R_{j k} \\
K_{i}=\frac{S_{j}}{\sum S_{j}} .
\end{gathered}
$$

\section{Case illustration}

Company A wants to get better alternatives for its firm. Following supplier selection, criteria are used to evaluate the ranks of Alternatives. In the literature survey it is found that Indian automobile industries are depended on 85 criteria (Sagar and Singh 2012). Out of 85 criteria major 
affecting 21 criteria is selected in this study. These criteria are standing as $\mathrm{C} 1, \mathrm{C} 2, \mathrm{C} 3, \ldots, \mathrm{C} 21$ for price, quality, quality standards, etc. [24].

\subsection{Application with AHP}

\section{1a Priority weight of decision criteria}

The buyer must now develop a set of pairwise comparison to define the relative importance of the criteria. Before developing a pairwise comparison matrix, communities need to be checked for effective factor analysis for supply chain coordination criteria. The factor comparison weighing score is computed using Eqs. (6), (7), (8) and (9) [24]. However, judgments are not always perfectly consistent; all criteria are judged moderately based on experiences of decision makers.

The proposed evaluation is performed based on the importance of selection criteria to the decision maker as well as his/her perception of the supplier's performance with respect to these criteria. The final weights for price, quality, quality standard, etc. are $0.105,0.102,0.055$, etc., respectively shown in table 1 [24].

5.1b Priority weight of alternatives and consistency analysis AHP allows individuals to use their own personal psychometric scales for making the required pairwise comparisons. Computations of consistency ratio are somewhat more involved and calculated by Eq. (17) is 0.930698 , which can be shown that consistency is acceptable.

Next, the five suppliers must be compared pairwise for each criterion. The crisp relative weight of supplier A1, A2, A3, A4 and A5 are 0.168, 0.085. 0.157. 0.378 and 0.189, respectively [24]. According to Eqs. (14), (15), (16) and (17), calculation of consistency ratio (CR) is as follows-

$$
\begin{gathered}
\lambda_{\max }=\frac{1140.702044}{21}=54.319 ; \\
C I=\frac{54.319-21}{21-1}=1.66595 \\
R I=1.98 \times \frac{21-2}{21}=1.79 ; \quad C R=\frac{1.66595}{1.79}=0.930698 .
\end{gathered}
$$

\section{1c Global priority weight of alternatives}

Evaluation of global ranking of suppliers is performed based on obtained local fuzzy relative weight according to Eqs. (18), (19) and (20) [24]. For the given supplier 21 weights are computed and the results of these composite relative weights $0.166,0.074,0.153,0.386$ and 0.189 are computed as supplier score and are shown in table 2.

\subsection{Application with fuzzy TOPSIS}

Here, we have considered five most significant partners of the case company $\mathrm{A} 1, \mathrm{~A} 2, \mathrm{~A} 3, \mathrm{~A} 4$ and $\mathrm{A} 5$ to prioritize

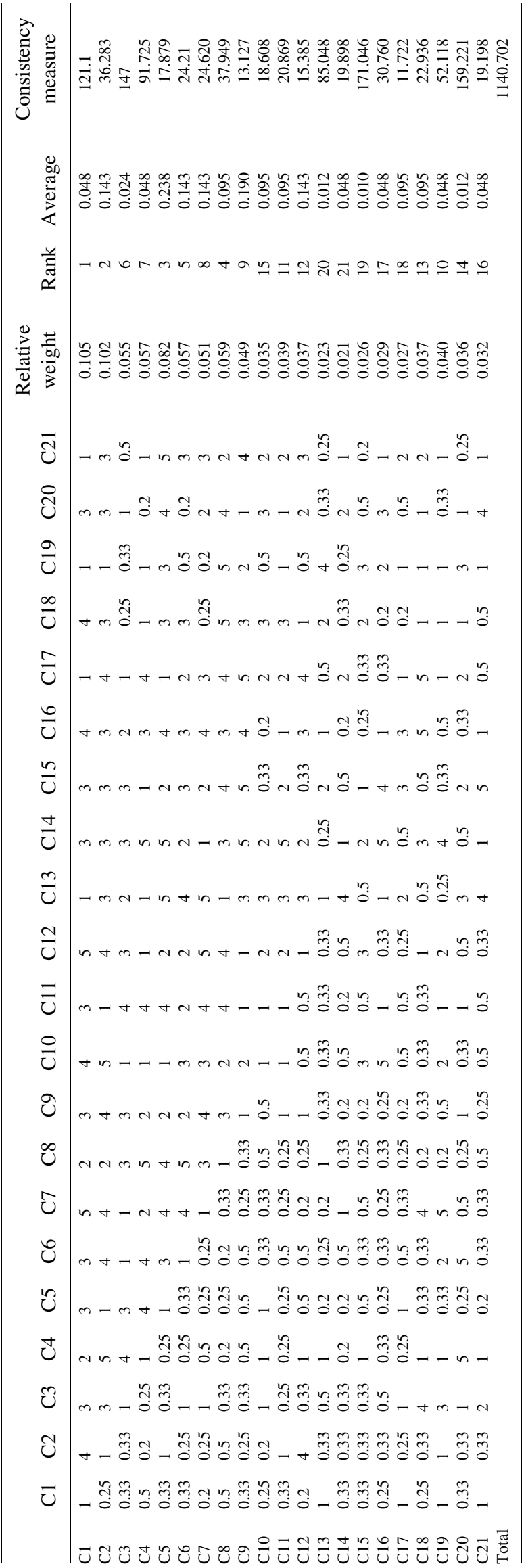




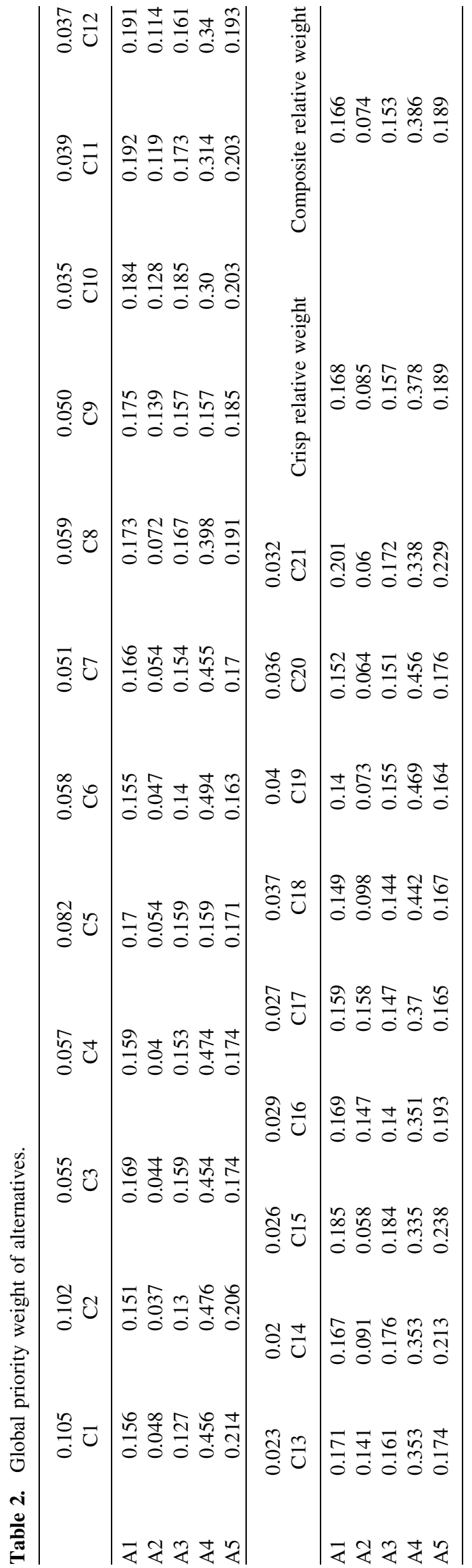

them. The following steps of fuzzy TOPSIS explain the method of determining the priority of alternatives:

Step 1: First of all; linguistic scales were set to assess both the relative importance of criteria and performance of each company for each criterion. The scales and related fuzzy triangular numbers as in Rajak et al [24] are used here.

Step 2: Normalization of the fuzzy decision matrix for sustainable criteria using Eq. (21). Considering the different weights of each criterion, the weighed and normalized decision matrix is computed by multiplying the important weights of evaluation criteria and the values in the normalized fuzzy decision matrix using Eq. (22), as shown in table 3.

Step 3: In this step, determination of the FPIS $A^{+}$and FNIS $A^{-}$is computed as shown in tables 4 and 5.

Step 4: In this step, then n-dimensional separation distance of each alternative $i=1,2,3, \ldots, m$ to the FPIS $d_{i}^{+}$and to the FNIS $d_{i}^{-}$are computed using Eqs. (23), (24) and (25), as shown in table 6.

Step 5: In this step alternatives closeness index is calculated by Eq. (26). For each competitive alternative the relative closeness of the potential location with respect to the ideal solution is $0.5555,0.4753,0.5,0.7154$ and 0.5529 . Therefore the maximum value is the best one and the optional alternative has a value closeness index closer to 1 , so it is acceptable condition.

Step 6: According to the closeness coefficient, the ranking of the alternatives can be determined as shown in table 6 .

\subsection{Validation with FIS analysis using MATLAB toolbox}

Here, we illustrate the proposed expert system in prioritizing five suppliers of automobile parts supplier A1, A2, A3, A4 and A5. These alternatives using the criteria cost, quality, delivery time, financial position, flexibility and general reputation. The linguistic variables for criteria and their corresponding membership functions are followed by Rajak et al [24]. We selected the centroid method, which returns the center of the area under the curve and satisfies the selection criteria. This is followed by rank ordering of the sustained suppliers. We selected the SAW due to its simplicity, popularity to practitioners and the best performance results which it achieves compared to other methods [2] (figure 1).

Considering the experts the cost has a triangular membership function and trapezoidal membership function with minimum cost of 50,00,000 and maximum of 1,00,00,000. For the quality, flexibility and general reputation linguistic triangular fuzzy number (less, medium, high) and Financial position linguistic triangular and trapezoidal fuzzy numbers are considered. For delivery time also linguistic triangular and trapezoidal fuzzy numbers with minimum 1 day and maximum 3 days are considered. The output of the system 
Table 3. Weighed normalized fuzzy decision matrix.

\begin{tabular}{llllll}
\hline & \multicolumn{1}{c}{ A1 } & A2 & A3 & A4 & A5 \\
\hline Cost & $(0.24,0.4,0.5)$ & $(0.18,0.32,0.5)$ & $(0.24,0.4,0.5)$ & $(0.24,0.4,0.5)$ & $(0.16,0.3,0.4)$ \\
Quality & $(0.18,0.32,0.5)$ & $(0.12,0.24,0.4)$ & $(0.12,0.24 .0 .4)$ & $(0.32,0.5,0.5)$ & $(0.16,0.3,0.4)$ \\
Delivery & $(0.24,0.4,0.5)$ & $(0.18,0.32,0.5)$ & $(0.18,0.32,0.5)$ & $(0.32,0.5,0.5)$ & $(0.16,0.3,0.4)$ \\
Technical capability & $(0.24,0.32,0.5)$ & $(0.06,0.16,0.3)$ & $(0.18,0.32,0.5)$ & $(0.32,0.5,0.5)$ & $(0.24,0.4,0.5)$ \\
Financial & $(0.24,0.32,0.5)$ & $(0.18,0.32,0.5)$ & $(0.18,0.32,0.5)$ & $(0.32,0.5,0.5)$ & $(0.24,0.4,0.5)$ \\
Reputation & $(0.12,0.24,0.4)$ & $(0.24,0.4,0.5)$ & $(0.12,0.24 .0 .4)$ & $(0.24,0.4,0.5)$ & $(0.32,0.5,0.5)$ \\
\hline
\end{tabular}

Table 4. Fuzzy positive-ideal solution $A^{+}$(FPIS).

\begin{tabular}{lccccc}
\hline & A1 & A2 & A3 & A4 & A5 \\
\hline Cost & 0.16 & 0.21 & 0.16 & 0.16 & 0.24 \\
Quality & 0.21 & 0.27 & 0.27 & 0.10 & 0.24 \\
Delivery & 0.16 & 0.21 & 0.21 & 0.10 & 0.24 \\
Technical capability & 0.18 & 0.32 & 0.21 & 0.10 & 0.16 \\
Financial & 0.18 & 0.21 & 0.21 & 0.10 & 0.16 \\
Reputation & 0.27 & 0.16 & 0.27 & 0.16 & 0.10 \\
& 1.16 & 1.38 & 1.33 & 0.72 & 1.14 \\
\hline
\end{tabular}

Table 5. Fuzzy negative-ideal solution $A^{-}$(FNIS).

\begin{tabular}{lccccc}
\hline & A1 & A2 & A3 & A4 & A5 \\
\hline Cost & 0.25 & 0.22 & 0.25 & 0.25 & 0.16 \\
Quality & 0.25 & 0.18 & 0.18 & 0.33 & 0.19 \\
Delivery & 0.25 & 0.22 & 0.22 & 0.29 & 0.16 \\
Technical capability & 0.31 & 0.15 & 0.30 & 0.39 & 0.34 \\
Financial & 0.21 & 0.20 & 0.20 & 0.27 & 0.23 \\
Reputation & 0.18 & 0.28 & 0.18 & 0.28 & 0.33 \\
& 1.45 & 1.25 & 1.33 & 1.81 & 1.41 \\
\hline
\end{tabular}

Table 6. Closeness coefficient with ranking of alternatives.

\begin{tabular}{lccl}
\hline Alternative & $d_{i}^{+}$ & $d_{i}^{-}$ & \multicolumn{1}{c}{$C_{i}$} \\
\hline A1 & 1.16 & 1.45 & 0.5555 \\
A2 & 1.38 & 1.25 & 0.4753 \\
A3 & 1.33 & 1.33 & 0.5 \\
A4 & 0.72 & 1.81 & 0.7154 \\
A5 & 1.14 & 1.41 & 0.5529 \\
\hline
\end{tabular}

which is the evaluation result is a linguistic triangular fuzzy membership function for rejection, under consideration and accept. Regarding the experts and taking the criteria into considerations, the following rules are derived as shown in figure 2 .

The linguistic fuzzy variables, i.e. criteria and rating are defuzzified in a numeric value. This is followed by rank ordering of the suppliers using SAW. As the result of each alternative, the score $S_{j}$ is $6.95,6.3,6.5,7.44$ and 6.52 respectively. Then the scores are normalized by Eq. (28). Consequently, we got the rating points of suppliers in terms of normalized index $K_{i}$ such as $0.205,0.186,0.192,0.219$ and 0.198 respectively as an output of FIS (figure 3) (table 7).

\section{Results and discussions}

Decision makers of any organization face the uncertainty from experiences and perceptions in this kind of decision making problems. To overcome this limitation MCDM approach has been adopted in this research paper. Here, we compare the three different proposed fuzzy models with its deterministics. The proposed methodology has been applied with the help of real life case study in the automotive manufacturing industry. Data for five suppliers are collected from the automobile firm for a periodic demand of vehicle parts. Based on these data a heuristic fuzzy model is created which depicts those suppliers A4, A5 and A1 are the top three suppliers as shown in table 7.

\subsection{Cost analysis}

The approach of the procurement department is to issue the order among the best three suppliers to avoid the biases. Each supplier has definite capacity to supply materials as given in table 8 . Each supplier supply faulty material according to the percentage of defective items calculated and each one of them supply, according to their own pace and the percentages of delays in delivery are also provided in table 9 for each supplier. The firm's assignment schedule is moderately stiff and as a result delay in delivery incurs the overall cost of the project. Delay cost is calculated by the experts of the firm, which is closely 3.5 lakhs INR per day. The cost incurs due to substandard supply are generally converted into delay cost as stated by the firm's manager and calculated using the first component of Eqs. (1), (2), (3), (4) and (5).

The ranking order of five suppliers based on their supply chain coordination has been determined as $\mathrm{A} 4>\mathrm{A} 5>$ $\mathrm{A} 1>\mathrm{A} 3>\mathrm{A} 2$. The supplier "A4" is the best sustainable supplier for this case study problem. Apart from this three other basic objectives are also illustrated simultaneously. In the cost analysis of the top three suppliers, we computed that total procurement cost is 55,300,000, total number of faulty items is 22 and total number of delay days of delivery is 22 out of 1,250 orders. 


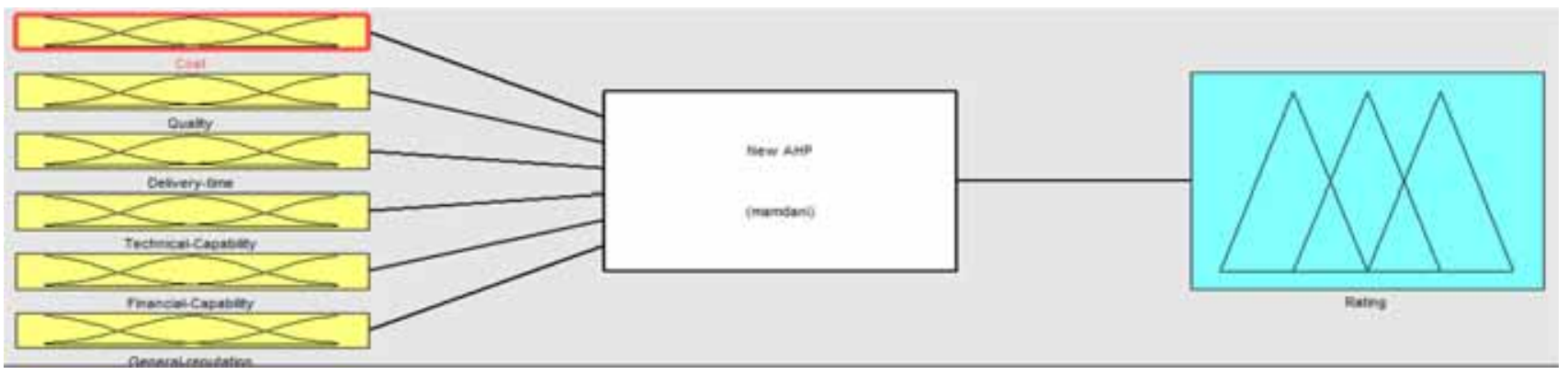

Figure 1. The input and output members.

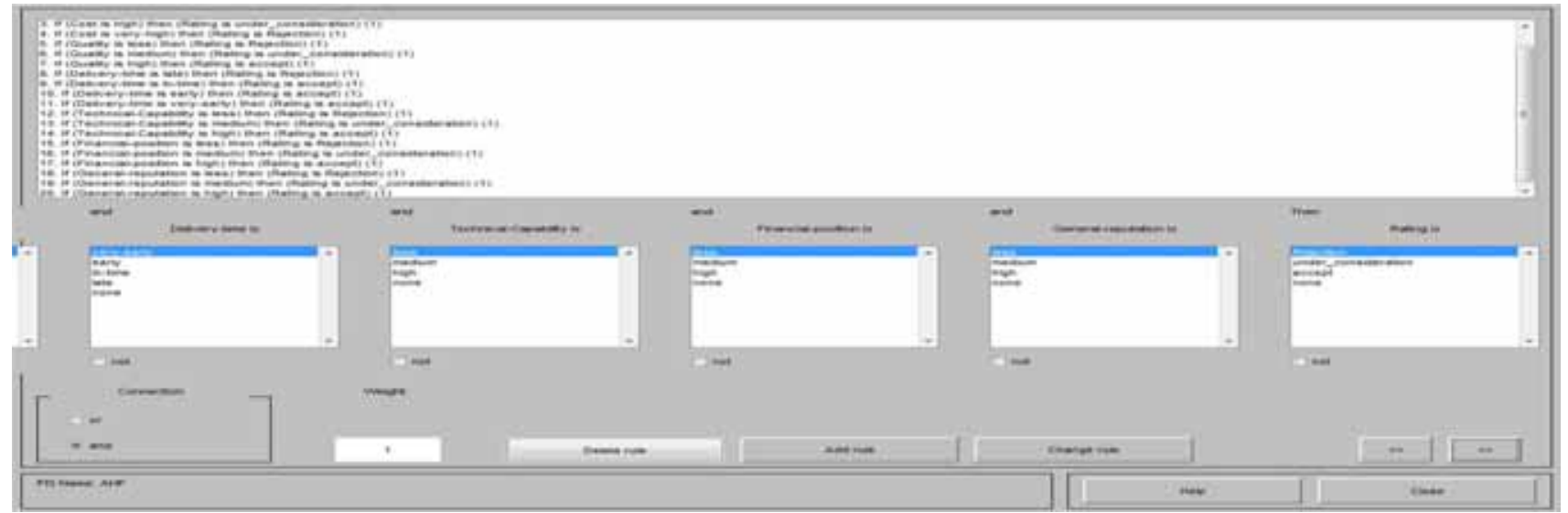

Figure 2. Proposed rules in FIS.

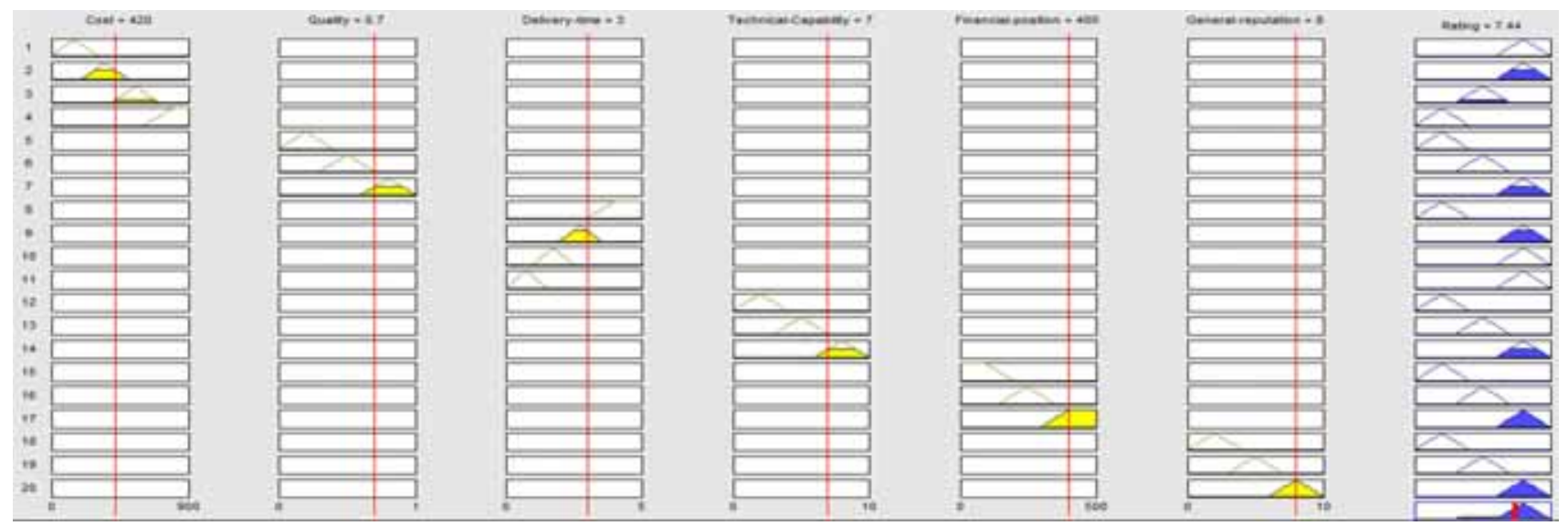

Figure 3. Rule viewer for most suitable alternatives A4.

\section{Conclusion and future aspects}

This paper presents the assessment of fuzzy models based multi-criteria decision making systems. AHP, fuzzy TOPSIS and FIS MATLAB fuzzy tool all three approaches are used to evaluate decision process since the criteria are both qualitative and quantitative for this case study. The uniqueness of this work lies in practicing simultaneously three different decision making techniques in solving this MCDM problems and computations of total procurement cost, total number of faulty items and delay days of delivery are also accomplished with the validation of AHP and fuzzy TOPSIS results using the FIS MATLAB toolbox. As per the time complexity, a heuristic FIS model presented in this work will reduce the computational time effectively when compared to the similar other research works done in the 
Table 7. Results of all the three models in terms of ranking of alternatives.

\begin{tabular}{|c|c|c|c|c|c|}
\hline \multirow[b]{2}{*}{ Alternatives } & \multirow[b]{2}{*}{ AHP } & \multirow[b]{2}{*}{ Fuzzy TOPSIS } & \multicolumn{2}{|c|}{ FIS model using MATLAB toolbox } & \multirow[b]{2}{*}{ Ranking } \\
\hline & & & $S_{j}$ & $K_{i}$ & \\
\hline A1 & 0.166 & 0.5555 & 6.95 & 0.205 & 3 \\
\hline A2 & 0.074 & 0.4753 & 6.3 & 0.186 & 5 \\
\hline A3 & 0.153 & 0.5 & 6.5 & 0.192 & 4 \\
\hline A4 & 0.386 & 0.7154 & 7.44 & 0.219 & 1 \\
\hline A5 & 0.189 & 0.5529 & 6.72 & 0.198 & 2 \\
\hline
\end{tabular}

Table 8. Collected supplier's details data from the firm.

\begin{tabular}{lcccc}
\hline Alternatives & Order quantity/week & Unit cost & Percent defects/unit & Percent delay \\
\hline A1 & 400 & 35,000 & 2.2 & 2.32 \\
A2 & 450 & 38,000 & 3.1 & 3.28 \\
A3 & 500 & 37,000 & 2.5 & 3.12 \\
A4 & 350 & 34,000 & 1.3 & 1.12 \\
A5 & 500 & 38,500 & 1.6 & 1.45 \\
\hline
\end{tabular}

Table 9. Cost analysis of the firm.

\begin{tabular}{lrccc}
\hline Alternatives & Order & Defective & Late delivery & Cost \\
\hline A4 & 350 & 5 & 4 & $11,900,000$ \\
A5 & 500 & 8 & 8 & $19,250,000$ \\
A1 & 400 & 9 & 10 & $14,000,000$ \\
& 1250 & 22 & 22 & $45,150,000$ \\
Quality cost & & & & $2,450,000$ \\
Delay cost & & & & $7,700,000$ \\
Total procurement cost & & & $55,300,000$ \\
\hline
\end{tabular}

past. Although fuzzy AHP and fuzzy TOPSIS methods are equally adequate to deal with the lack of precision of score of alternatives as well as the relative importance of different criteria, it is worth noting that MATLAB Fuzzy program is more appropriate than these two when there are more criteria and suppliers.

The problem is formulated using a multi-objective mathematical model which reflects the essential sustainable criteria of this research. Further research will consider: (1) to design the expert system to solve the prioritization problems using other fuzzy-based MCDM approaches; (2) score among the criteria were obtained in an interview with experts. In order to improve the results more experts can be interviewed; (3) optimization of the results with the use of optimal solutions.

\section{References}

[1] Thrulogachantar P and Zailani S 2011 The influence of purchasing strategies on manufacturing performance. $J$. Manuf. Technol. Manag. 22: 641-663
[2] Zanakis S, Solomon A, Wishart N and Dublish S 1998 Multiattribute decision-making: a simulation comparison of select methods. Eur. J. Oper. Res. 107: 507-529

[3] Dickson G W 1966 An analysis of vendor selection: Systems and decisions. J. Purchas. 1(2): 5-17

[4] Weber C, Current J R and Benton W C 1991 Vendor selection criteria and method. Eur. J. Oper. Res. 50(1): 2-18

[5] Sagar M K and Singh D 2012 Supplier selection criteria: Study of automobile sector in India. Int. J. Eng. Res. Dev. 4(4): 34-39

[6] Ghosh T, Chakraborty T and Dan P K 2012 An effective AHP based metaheuristic approach to solve supplier selection problem. Int. J. Procurement Manag. 5(2): 140-159

[7] Rajak A K, Niraj M and Kumar S 2015 Multi-criteria decision making method \& value engineering: A new concept in vendor selection. Int. J. Current Adv. Res. 4(7): 171-173

[8] Ertugrul I and Karakasoglu N 2009 Performance evaluation of Turkish cement firms with fuzzy analytic hierarchy process and TOPSIS methods. Expert Syst. Appl. 36(1): 702-715

[9] Balli S and Korukoglu S 2009 Operating system selection using fuzzy AHP and TOPSIS methods. Math. Comput. Appl. 14(2): 119-130

[10] Chamodrakas I, Alexopoulou N and Martakos D 2009 Customer evaluation for order acceptance using a novel class of fuzzy methods based on TOPSIS. Expert Syst. Appl. 36(4): 7409-7415

[11] Dagdeviren M, Yavuz S and Kilinc N 2009 Weapon selection using the AHP and TOPSIS methods under fuzzy environment. Expert Syst. Appl. 36(4): 8143-8151

[12] Wang Y J and Lee H S 2007 Generalizing TOPSIS for fuzzy multiple-criteria group decision-making. Comput. Math. Appl. 53: 1762-1772

[13] Wang Y M, Luo Y and Hua Z 2008 On the extent analysis method for fuzzy AHP and its applications. Eur. J. Oper. Res.. 186: 735-747

[14] Ye F and Li Y N 2009 Group multi-attribute decision model to partner selection in the formation of virtual enterprise 
under incomplete information. Expert Syst. Appl. 36(5): 9350-9357

[15] Junior F R L, Osiro L and Carpinetti L C R 2014 A comparison between fuzzy AHP and fuzzy TOPSIS methods to supplier selection. Appl. Soft Comput. 21: 194-209

[16] Shukla R K, Garg D and Agarwal A 2014 An integrated approach of fuzzy AHP and fuzzy TOPSIS in modeling supply chain coordination. Prod. Manuf. Res. 2(1): 415-437

[17] Hwang C L and Yoon K 1981 Multiple attribute decision making-methods and application. Springer Verlag. New York

[18] Hsieh T Y, Lu S T and Tzeng G H 2004 Fuzzy MCDM approach for planning and design tenders selection in public office buildings. Int. J. Project Manag. 22: 573-584

[19] Safari H and Anjali M 2014 A fuzzy TOPSIS approach for ranking of supplier: A case study of ABZARSAZI company. Social Basic Sci. Res. Rev. 2(10): 429-444
[20] Tsoukalas L and Uhrig R 1997 Fuzzy and neural applications in engineering. Wiley, New York

[21] Carrasco E, Rodriguez J, Punal A, Roca E and Lema J 2002 Rule-based diagnosis and supervision of a pilot-scale wastewater treatment plant using fuzzy logic techniques. Expert Syst. Appl. 22: 11-20

[22] Setnes M, Naute Lemke H and Kaymak U 1998 Fuzzy arithmetic-based interpolative reasoning for nonlinear dynamic fuzzy systems. Eng. Appl. Artif. Intell. 11: 781-789

[23] Al-Najjar B and Alsyouf I 2003 Selecting the most efficient maintenance approach using fuzzy multiple criteria decision making. Int. J. Prod. Econom. 84: 85-100

[24] Rajak A K, Niraj M and Kumar S 2016 Supplier selection heuristic model by integrating Matlab with fuzzy AHP and fuzzy TOPSIS methods. Kasmera 44: 294-327 